\title{
Stability of Dabigatran Etexilate in Manufacturer's Blister Pack, Unit-Dose Packaging, and Community Pharmacy Blister Pack
}

\author{
Erica H Z Wang, Jennifer L Bolt, Diane Décarie, William Semchuk, and Mary H H Ensom
}

\begin{abstract}
Background: Dabigatran, a direct thrombin inhibitor, is indicated for the prevention and treatment of venous thromboembolism and for stroke prophylaxis in atrial fibrillation. The manufacturer recommends that dabigatran etexilate be retained in the original packaging until administration. Currently, no information exists about the stability of dabigatran etexilate outside its original packaging
\end{abstract}

Objective: To evaluate the stability of dabigatran etexilate capsules over 120 days, with storage in the manufacturer's original packaging, in unitdose packaging, and in community pharmacy blister packaging.

Methods: Commercially available dabigatran etexilate capsules (110 mg) were stored at room temperature $\left(25^{\circ} \mathrm{C}\right)$ in the manufacturer's original blister pack, in unit-dose packaging, or in community pharmacy blister packs. Samples were collected from each container daily for the first 3 days, weekly up to 28 days, every other week until day 98 , and at day 120. Suspensions were prepared, $\mathrm{pH}$ was evaluated, and samples were stored at $-85^{\circ} \mathrm{C}$ until analysis. Each sample was analyzed in duplicate by a validated, stability-indicating high-performance liquid chromatography - ultraviolet detection method. The capsules were considered stable if they maintained at least $90 \%$ of the initial concentration.

Results: Dabigatran etexilate capsules maintained $100.4 \%$ of the original concentration with 120 days of storage in the manufacturer's original blister pack, $98.7 \%$ with storage in unit-dose packaging, and $98.0 \%$ with storage in community pharmacy blister packs. There were no notable changes in appearance, ease of suspension of the capsule content, or $\mathrm{pH}$ over the 120-day period.

Conclusion: Dabigatran etexilate 110-mg capsules were stable for 120 days with storage at room temperature in 3 types of packaging widely used in hospital and community settings.

Key words: dabigatran, dabigatran etexilate, drug stability, drug packaging, liquid chromatography

\section{RÉSUMÉ}

Contexte : Le dabigatran, un inhibiteur direct de la thrombine, est approuvé pour la prévention et le traitement des événements thromboemboliques veineux et pour la prophylaxie de l'accident vasculaire cérébral en présence de fibrillation auriculaire. Le fabricant recommande que le dabigatran etexilate soit gardé dans le conditionnement d'origine jusqu’à l'administration. Il n'existe aucune donnée sur la stabilité du dabigatran etexilate hors du conditionnement d'origine.

Objectif : Évaluer la stabilité de capsules de dabigatran etexilate sur une période de 120 jours lorsqu'elles sont entreposées dans : le conditionnement d'origine du fabricant, un conditionnement unitaire ou un pilulier de type plaquette alvéolée préparé en pharmacie communautaire.

Méthodes : Des capsules de $110 \mathrm{mg}$ de dabigatran etexilate, disponibles sur le marché, ont été entreposées à température ambiante $\left(25^{\circ} \mathrm{C}\right)$ soit dans la plaquette alvéolée d'origine du fabricant, soit dans un conditionnement unitaire, soit dans un pilulier de type plaquette alvéolée préparé en pharmacie communautaire. Des échantillons ont été prélevés de chaque type d'emballage : quotidiennement pour les 3 premiers jours, hebdomadairement pour les 28 jours suivants, puis toutes les deux semaines jusqu'au jour 98 , et au jour 120 . Des suspensions ont été préparées, le $\mathrm{pH}$ mesuré et les échantillons entreposés à $-85^{\circ} \mathrm{C}$ jusqu’à l'analyse. Chaque échantillon a été soumis à une double analyse à l'aide d'une épreuve validée mesurant la stabilité par chromatographie liquide haute performance avec détection ultraviolette. Les capsules étaient considérées comme stables si elles conservaient au moins $90 \%$ de leur concentration initiale.

Résultats : Au bout des 120 jours, les capsules de dabigatran etexilate ont conservé $100,4 \%$ de leur concentration de départ lorsqu'entreposées dans les plaquettes alvéolées d'origine du fabricant, 98,7 \% lorsqu'entreposées dans un conditionnement unitaire et 98,0 \% lorsqu'entreposées dans un pilulier de type plaquette alvéolée préparé en pharmacie communautaire. Aucun changement notable de l'apparence, du pH et de la facilité de la mise en suspension du contenu de la capsule n'a été observé pendant la période de 120 jours.

Conclusion : Les capsules de $110 \mathrm{mg}$ de dabigatran etexilate sont demeurées stables pendant la période de 120 jours d'entreposage à température ambiante dans trois types de conditionnement largement utilisés dans les hôpitaux et les pharmacies communautaires.

Mots clés : dabigatran, dabigatran etexilate, stabilité des médicaments, conditionnement, chromatographie liquide 


\section{INTRODUCTION}

$\mathrm{T}$ he variety of agents available for anticoagulation has expanded greatly over the past decade, and vitamin $\mathrm{K}$ antagonists are no longer the only oral option for treating thromboembolic conditions. In particular, direct thrombin inhibitors and factor $\mathrm{Xa}$ inhibitors are gaining popularity for the prevention and treatment of venous thromboembolism and for stroke prophylaxis in atrial fibrillation. One of the direct thrombin inhibitors, dabigatran, was the first novel oral anticoagulant to become available worldwide. It received approval in Europe (from the European Medicines Agency) in 2008 and in Canada (from Health Canada) and the United States (from the Food and Drug Administration) in 2010. ${ }^{1-3}$ Dabigatran is approved for multiple indications, including stroke prophylaxis in atrial fibrillation, prophylaxis of venous thromboembolism after hip and knee arthroplasty, and treatment of venous thromboembolism in those who have received an anticoagulant parenterally for 5-10 days. ${ }^{1-3}$

Dabigatran is a highly selective direct thrombin inhibitor. It rapidly produces competitive, reversible, and concentrationdependent inhibition of the thrombin molecule within the clotting cascade. Dabigatran etexilate is currently available as 75-mg, 110-mg, and 150-mg capsules. ${ }^{1-3}$ Each capsule contains multiple pellets, each about $1 \mathrm{~mm}$ in diameter, composed of a tartaric acid core surrounded by dabigatran etexilate, the prodrug of dabigatran. ${ }^{1-4}$ Once a capsule is consumed, the dabigatran etexilate is rapidly converted to its active form, dabigatran. The core of each pellet ensures an acidic microenvironment, which promotes drug dissolution and absorption, independent of the patient's gastric $\mathrm{pH} .{ }^{4}$ The manufacturer reported that in its solid state, dabigatran etexilate was stable for 12 months at room temperature with $60 \%$ relative humidity, and it degraded less than $0.5 \%$ after 4 weeks in a closed container stored at $70^{\circ} \mathrm{C} .{ }^{1-3}$ Although the drug is not sensitive to irradiation with visible light, the presence of the acidic core leads to significant acceleration of the degradation process in the presence of moisture. ${ }^{5}$ Hence, the product monographs clearly recommend that the product be protected from moisture during storage. ${ }^{1-3}$

Real-world use of dabigatran etexilate has highlighted several practical concerns regarding its stability. Initially, the manufacturer supplied dabigatran etexilate in 2 different types of packaging: blister packages and bottles. The manufacturer recommends that dabigatran etexilate be stored at a temperature between $15^{\circ} \mathrm{C}$ and $30^{\circ} \mathrm{C}$ and that it be retained in the original packaging until administration. ${ }^{1-3}$ The bottled product contains a desiccant, which protects the drug from moisture, and the capsules may be stored in the manufacturer's original bottle, with the lid tightly closed, for up to 4 months. However, this type of packaging is no longer available in Canada. ${ }^{6}$ The blister package, currently the only type of packaging available in Canada, uses foil packaging, which can be difficult to open for those with visual impairment or poor manual dexterity. These storage- related issues pose practical challenges for hospital pharmacies, community pharmacies, and patients.

In the hospital setting, pharmacies use unit-dose packaging to enhance medication safety and minimize errors related to medication administration. Unit-dose packages generally consist of a single medication packaged in individual plastic bags with explicit drug-specific labelling. Workload demands and efforts to increase efficiency with automation mean that medications are often prepackaged, sometimes months in advance. However, given the reported relative instability of dabigatran etexilate once it is removed from the original packaging, hospital pharmacies cannot prepackage this medication; it can be packaged and labelled only after an order has been written. An alternative process is to manually separate, label, and package the manufacturer's original blister-packaged product by the hospital pharmacy. Both alternatives increase workload and disrupt the flow of distribution services within a hospital pharmacy dispensary. Community pharmacies are also challenged by stability issues for this medication. The manufacturer's storage requirements prevent inclusion of dabigatran etexilate capsules in blister packs or dosettes, which may increase the risk of noncompliance with therapy and the subsequent risk of thromboembolic events due to underdosing or hemorrhagic events due to overdosing.

No explicit information regarding the stability of dabigatran etexilate and its degradation is available in the literature or from the manufacturer. The manufacturer's documents note that the drug's degradation rate is accelerated by moisture and extreme temperatures, but it is unknown whether the extent of degradation in a unit-dose package or a community pharmacy blister pack will be clinically relevant. ${ }^{5}$ Recently, Bernardi and others developed and validated a liquid chromatography method for determining the stability of dabigatran etexilate, but a systematic review of the literature revealed that this method has not yet been used to determine real-world stability of dabigatran etexilate in storage environments other than the manufacturer's original packaging. The objective of this study was to evaluate the stability of dabigatran etexilate over time with storage at room temperature in 3 different clinically relevant and practical environments: manufacturer's original blister pack, unit-dose packaging, and community pharmacy blister packaging.

\section{METHODS}

The primary outcome of the study was the concentration of dabigatran etexilate after storage at $25^{\circ} \mathrm{C}$ in the manufacturer's original blister pack (Pradaxa $110 \mathrm{mg}$; Boehringer Ingelheim, Burlington, Ontario; lot 205749, expiry April 2015), in unitdose packaging (Unit Dose System, Medical Packaging Inc, Ringoes, New Jersey), and in community pharmacy blister packs (Medpaks, Healthmark Industries Company Inc, Fraser, Michigan) over a 120-day period, with sampling on days 1, 2, 3, $4,7,14,21,28,42,56,70,84,98$, and 120 . The secondary 
outcome was the $\mathrm{pH}$ of dabigatran etexilate over the same 120 day period.

\section{Physical Characteristics}

The $\mathrm{pH}$ was evaluated at the time of preparation, daily for 3 days, weekly up to 28 days, every other week until day 98 , and at day 120. At each time point, 3 capsules in each packaging group were emptied. The contents of each capsule were crushed and diluted in high-performance liquid chromatography (HPLC)-grade water (Fisher Scientific, Whitby, Ontario; lots 134437 and 135622) to a concentration of $20 \mathrm{mg} / \mathrm{mL}$, and the $\mathrm{pH}$ was then measured. The $\mathrm{pH}$ meter (model 8000, VWR International, Mississauga, Ontario) was calibrated on each study day using commercially available standards ( $\mathrm{pH} 7.00$ and 4.00, Fisher Scientific; lots 116554 and 116550, respectively; expiry November 2013 for both). Immediately following $\mathrm{pH}$ measurement, 1.5-mL samples from each diluted sample were transferred to polypropylene freezer vials (VWR International) and stored at $-85^{\circ} \mathrm{C}$ until analysis by a published, stability-indicating HPLC-ultraviolet detection method $^{7}$ that had been modified and validated in the authors' laboratory.

\section{Preparation of Stocks and Standards}

Stock solutions of dabigatran etexilate $1 \mathrm{mg} / \mathrm{mL}$ (Sequoia Research Products, Oxford, UK; lot100601-300d) were prepared in HPLC-grade methanol (Fisher Scientific; lot 134319) to construct the standard curve. Indomethacin powder (SigmaAldrich, Oakville, Ontario; lot 67H1609) diluted in HPLCgrade methanol to a concentration of $1 \mathrm{mg} / \mathrm{mL}$ was selected as the internal standard.

Standard solutions of dabigatran etexilate containing 0.150 $\mathrm{mg} / \mathrm{mL}$ of the internal standard were prepared in HPLC-grade methanol to final concentrations of 0.040, 0.050, 0.060, 0.080, 0.100 , and $0.120 \mathrm{mg} / \mathrm{mL}$. All standards were passed through a 13-mm diameter, 0.45- $\mu \mathrm{m}$ microfilter (Acrodisc GHP [Gelman hydrophilic propylene] filter, Waters Corporation Ltd; lot $21829235)$ to prevent injection of impurities onto the column.

A 6-point calibration curve was prepared, with a blank (water only) at the beginning of each run, to ensure that there was no carry-over from one run to the next. The range of this calibration curve $(0.040-0.120 \mathrm{mg} / \mathrm{mL})$ encompassed the diluted test concentration of dabigatran etexilate $(0.080 \mathrm{mg} / \mathrm{mL})$. The calibration curve was generated by least-squares regression of the peak area ratio of dabigatran etexilate to indomethacin (the internal standard) and the concentration of each dabigatran etexilate standard.

The precision of the assay was evaluated by intraday and interday validation methods. The intraday variability was determined by running stock solutions of dabigatran etexilate at concentrations of $0.040,0.070,0.090$, and $0.110 \mathrm{mg} / \mathrm{mL}$ in quadruplicate throughout a single day. The interday variability was determined by running the same analyte concentrations as used for the intraday validation in quadruplicate daily for 4 days. The accuracy of the assay was calculated as the mean deviation between nominal and observed concentrations. The mean, standard deviation, and coefficient of variation (CV) were calculated. The acceptable limit of the CV for precision was defined a priori as less than $10 \%$ and the acceptable limit for accuracy as greater than $90 \%$.

\section{Preparation of Samples}

On the day of analysis, the samples were thawed and mixed by vortex mixer for $10 \mathrm{~s}$. From each freezer vial, a $0.3-\mathrm{mL}$ sample was collected and combined with $0.3 \mathrm{~mL}$ of methanol; the solution was then centrifuged for $5 \mathrm{~min}$ at $5200 \mathrm{rpm}$ (model AccuSpin 1R; Fisher Scientific/Thermo Scientific, Ottawa, Ontario) and further diluted to $1 \mathrm{mg} / \mathrm{mL}$ in HPLC-grade methanol. The concentration of each sample was adjusted to $0.080 \mathrm{mg} / \mathrm{mL}$ with $0.150 \mathrm{mg} / \mathrm{mL}$ of the internal standard. Before injection onto the chromatographic column, each $10-\mu \mathrm{L}$ sample was filtered through an Acrodisc 0.45- $\mu \mathrm{m}$ microfilter. The samples were also evaluated for appearance and ease of suspension.

\section{HPLC Instrumentation}

The HPLC instrumentation (Waters Alliance System model 2690, Waters Corporation Ltd) consisted of a delivery pump, an automatic injector equipped with a $200-\mu \mathrm{L}$ injector, an Atlantis $\mathrm{dC1} 84.6 \mathrm{~mm} \times 250 \mathrm{~mm}$ column (Waters Corporation Ltd; lot 01423316613824), an Atlantis dC18 $3.9 \mathrm{~mm} \times 20 \mathrm{~mm}$ guard column (Waters Corporation Ltd; lot 0142331781), and an ultraviolet detector (Waters dual-absorbance detector, model 2487 ) set at $225 \mathrm{~nm}$. The mobile-phase gradient consisted of a 45:50:5 (v/v/v) mixture of methanol (Fisher Scientific; lot 1333730), acetonitrile (Fisher Scientific; lot 135590), and ammonium acetate (Sigma-Aldrich; lot 026K0667) at $\mathrm{pH} 5.0$ and room temperature. All solvents were HPLC-grade and were filtered before use. The range of the flow rate gradient was 1.5 to $0.8 \mathrm{~mL} / \mathrm{min}$

\section{Forced Degradation of Dabigatran Etexilate}

Dabigatran etexilate $20 \mathrm{mg} / \mathrm{mL}$ was prepared from commercially available dabigatran etexilate capsules (Pradaxa $110 \mathrm{mg}$ ) in HPLC-grade water. Intentional degradation was attempted by acid hydrolysis using $2 \mathrm{~N}$ hydrochloric acid $(\mathrm{HCl})$, base hydrolysis using $2 \mathrm{~N}$ sodium hydroxide $(\mathrm{NaOH})$, oxidation using $30.0 \%$ hydrogen peroxide $\left(\mathrm{H}_{2} \mathrm{O}_{2}\right)$, and thermal degradation by heating at $90^{\circ} \mathrm{C}$ for $2 \mathrm{~h}$. The $\mathrm{pH}$ of each solution was readjusted to its original level (about 2.30), and the concentration was adjusted to $0.080 \mathrm{mg} / \mathrm{mL}$. The solutions were filtered and injected 
onto the column. The resulting chromatograms were compared with a chromatogram obtained from the calibration curve to determine any changes in concentration, retention time, and peak shape.

\section{Statistical Analysis}

The means, standard deviations, and CVs for determination of precision and accuracy were calculated for the samples analyzed. For each type of packaging on each study day, the percentage of the initial concentration of dabigatran etexilate was calculated. The percentage of dabigatran etexilate remaining at the end of the study period was calculated from the concentration on day 120 , as determined by linear regression and the concentration observed on day 0 , according to the following formula: (concentration on the last day/concentration on day 0 ) $\times 100 \%$. The $95 \%$ confidence interval (CI) of the amount remaining on the last study day was calculated from the lower limit of the $95 \%$ CI of the slope of the curve relating concentration to time, via computer analysis, according to the following formula: lower limit of the $95 \% \mathrm{CI}$ of (concentration on the last day/concentration on day 0$) \times 100 \%$. Stability was defined as maintenance of at least $90 \%$ of the initial dabigatran etexilate concentration.

\section{RESULTS}

Regression analysis of the peak area ratio of dabigatran etexilate to indomethacin (internal standard) versus the concentration of each dabigatran etexilate standard demonstrated linearity over the range of concentrations, with coefficients of determination $\left(r^{2}\right)$ of 0.996 or higher $(n=4)$. The intraday and interday $\mathrm{CV}$ s were within acceptable limits (i.e., < 10\%): 3.66\% and $2.94 \%$, respectively, for the $0.040 \mathrm{mg} / \mathrm{mL}$ solution; $2.60 \%$ and $4.36 \%$, respectively, for the $0.070 \mathrm{mg} / \mathrm{mL}$ solution; $1.76 \%$ and $3.28 \%$, respectively, for the $0.090 \mathrm{mg} / \mathrm{mL}$ solution; and $2.35 \%$ and $3.72 \%$, respectively, for the $0.110 \mathrm{mg} / \mathrm{mL}$ solution. The intraday and interday accuracy results were also within acceptable limits (i.e., > 90\%): $94.23 \% \pm 2.53 \%$ and $96.91 \% \pm$ $3.09 \%$, respectively, for the $0.040 \mathrm{mg} / \mathrm{mL}$ solution; $97.67 \% \pm$ $1.65 \%$ and $95.73 \% \pm 4.27 \%$, respectively, for the $0.070 \mathrm{mg} / \mathrm{mL}$ solution; $96.79 \% \pm 2.13 \%$ and $96.72 \% \pm 3.28 \%$, respectively, for the $0.090 \mathrm{mg} / \mathrm{mL}$ solution; and $96.81 \% \pm 2.17 \%$ and $96.35 \% \pm 3.65 \%$, respectively, for the $0.110 \mathrm{mg} / \mathrm{mL}$ solution.

Retention times were $2.75 \mathrm{~min}$ for dabigatran etexilate and $1.99 \mathrm{~min}$ for the internal standard, indomethacin, on day 0 (Figure 1, panel A) and day 120 (Figure 1, panel F). No interfering peaks were generated by forced degradation of dabigatran etexilate with $\mathrm{HCl}, \mathrm{NaOH}, \mathrm{H}_{2} \mathrm{O}_{2}$, or heat (Figure 1, panels B$\mathrm{E}$, respectively). In general, the dabigatran etexilate peak shifted and/or decreased relative to the original chromatogram. The HPLC method developed was deemed capable of indicating stability. There were no notable changes in $\mathrm{pH}$. Throughout the study period, the mean $\mathrm{pH}( \pm$ standard deviation $)$ was $2.15 \pm$ 0.118 for capsules stored in the manufacturer's original blister pack, $2.15 \pm 0.134$ for capsules stored in unit-dose packaging, and $2.16 \pm 0.083$ for capsules stored in community pharmacy blister packs.

The HPLC analysis showed that capsules stored in all types of packaging maintained at least $98 \%$ of their original concentration for 120 days (Table 1). The lower limit of the $95 \%$ CI relating concentration to time, as determined by linear regression, indicated that dabigatran etexilate $110 \mathrm{mg}$ maintained $100.4 \%$ of the original concentration when stored for 120 days at room temperature in the manufacturer's original blister pack, $98.7 \%$ of the original concentration when stored in unit-dose packaging, and $98.0 \%$ of the original concentration when stored in community pharmacy blister packs, with $95 \%$ confidence. There were no notable changes in appearance or ease of suspension of capsule contents.

\section{DISCUSSION}

To the authors' knowledge, this is the first study of the stability of dabigatran etexilate in multiple environments other than the manufacturer's original packaging. Dabigatran etexilate 110 -mg capsules were stable for up to 120 days at $25^{\circ} \mathrm{C}$ in unit-dose packaging and community pharmacy blister packs, with all capsules maintaining at least $98 \%$ of their original concentration and no notable changes in $\mathrm{pH}$. The stability of $\mathrm{pH}$ is relevant because dabigatran etexilate is a prodrug enclosed in a pellet with an acidic core. This form ensures an acidic microenvironment to enhance the absorption of dabigatran. Any disruption in $\mathrm{pH}$ could alter the dissolution and absorption of the drug. The results of this study are clinically relevant because medications must often be taken out of the manufacturer's packaging and repackaged to facilitate distribution within an institution, to ensure safe administration of medications, or to enhance patients' compliance in the community.

Currently, the Canadian product monograph for dabigatran etexilate recommends, "Store between $15-30^{\circ} \mathrm{C}$. Store in the original package in order to protect from moisture". ${ }^{2}$ The European and US product monographs do not explicitly state the ideal temperature for storage, and none of the monographs provide guidance on the consequences of deviating from recommendations. ${ }^{1-3}$ Given the results of this study, pharmacists and clinicians may choose to repackage dabigatran etexilate to facilitate its distribution in institutional settings (e.g., hospitals or long-term care homes that use unit-dose packaging) when the benefits outweigh the risks. The results of the study may also be used to enhance compliance among patients in the community who need to receive their medications in blister packs.

This study had some limitations. The results cannot be extrapolated to other storage environments (e.g., dosettes that patients fill themselves), storage temperatures other than $25^{\circ} \mathrm{C}$, 


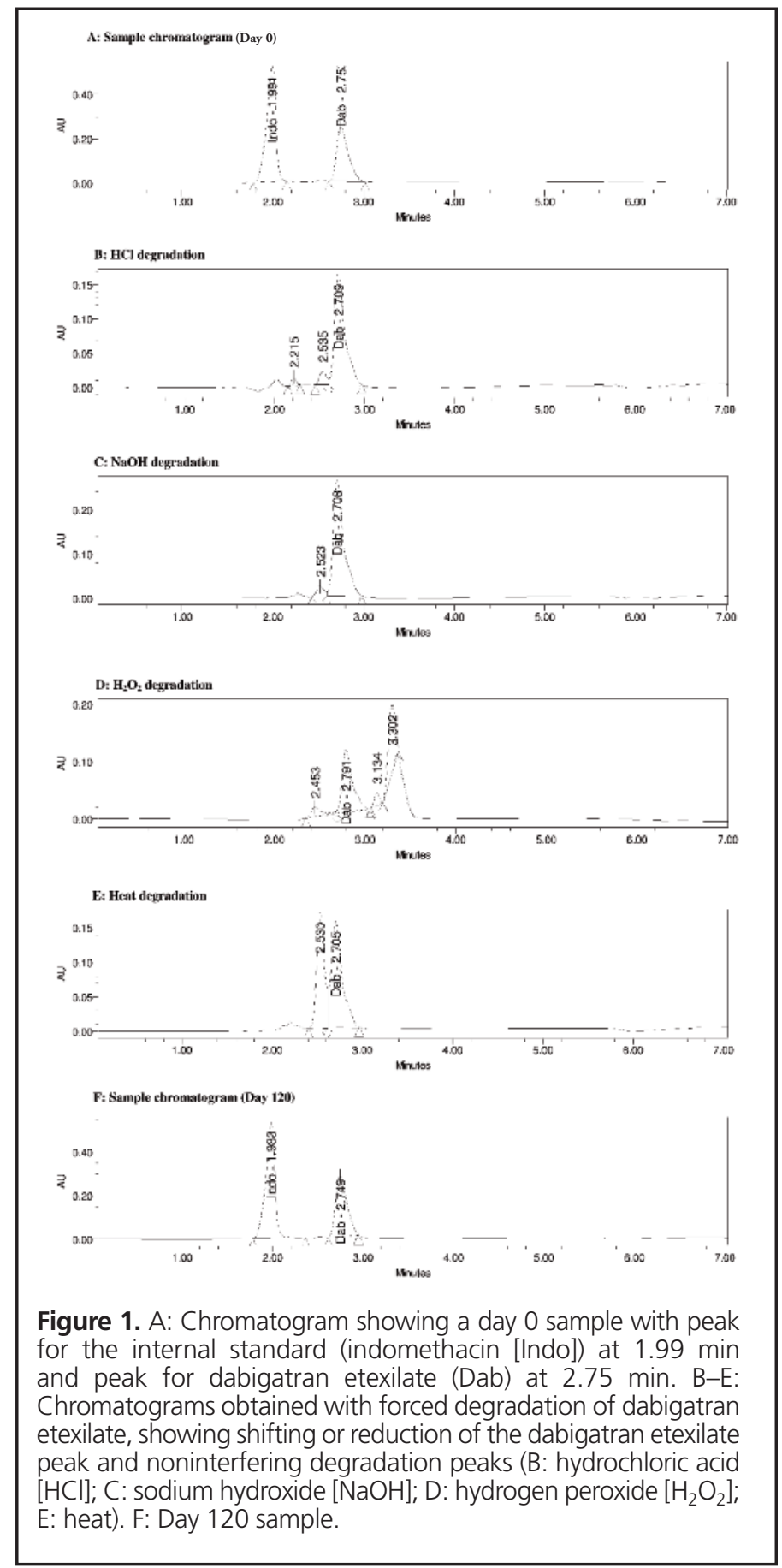

or storage times longer than 120 days in the studied environments. Also, because stability alone cannot guarantee bioavailability or efficacy, it is recommended that future clinical studies be conducted to evaluate the pharmacokinetics and pharmacodynamics of dabigatran etexilate after storage.

\section{CONCLUSIONS}

Serial quantitative assessments in the form of HPLC analysis and $\mathrm{pH}$ measurements showed that dabigatran etexilate 110-mg capsules were stable for up to 120 days with storage at $25^{\circ} \mathrm{C}$ in unit-dose packaging and community pharmacy blister packs (as well as the manufacturer's original blister packs), with all capsules maintaining at least $98 \%$ of their original concentration and no notable changes in $\mathrm{pH}$. The results of this study are applicable to community and institutional pharmacies, pharmacists, and clinicians. However, as stability alone cannot guarantee bioavailability or efficacy, future clinical pharmacokinetic and pharmacodynamics of dabigatran etexilate are warranted. 


\section{Table 1. Concentration of Dabigatran Etexilate in 3 Types of Packaging after Storage at $25^{\circ} \mathrm{C}$ for up to 120 Days}

\begin{tabular}{|c|c|c|c|c|}
\hline \multirow{3}{*}{$\frac{\text { Study Day }}{1}$} & \multicolumn{4}{|c|}{$\begin{array}{l}\text { Mean Concentration* } \pm \mathrm{SD}(\mathrm{mg} / \mathrm{mL}) \text { and } \\
\% \text { of Initial Concentration Remainingt }\end{array}$} \\
\hline & \multicolumn{2}{|c|}{$\begin{array}{l}\text { Manufacturer's } \\
\text { Blister Pack }\end{array}$} & $\begin{array}{l}\text { Unit-Dose } \\
\text { Packaging }\end{array}$ & $\begin{array}{l}\text { Community Pharmacy } \\
\text { Blister Packaging }\end{array}$ \\
\hline & $108.3 \pm 4.9$ & $(98.1)$ & $107.1 \pm 6.5 \quad(97.0)$ & $112.9 \pm 1.7(102.3)$ \\
\hline 2 & $106.6 \pm 3.4$ & $(96.5)$ & $108.1 \pm 4.8$ & $110.3 \pm 3.0$ \\
\hline 3 & $108.4 \pm 6.7$ & $(98.2)$ & $111.3 \pm 2.5(100.8)$ & $108.4 \pm 5.4$ \\
\hline 7 & $107.9 \pm 3.6$ & $(97.7)$ & $111.5 \pm 4.8(101.0)$ & $106.8 \pm 7.6$ \\
\hline 14 & $110.3 \pm 6.5$ & (99.9) & $109.3 \pm 3.5 \quad(99.2)$ & $109.9 \pm 2.1$ \\
\hline 21 & $107.5 \pm 5.1$ & $(97.4)$ & $110.3 \pm 3.8 \quad(99.9)$ & $109.9 \pm 2.6$ \\
\hline 28 & $110.0 \pm 3.7$ & (99.6) & $108.2 \pm 4.7 \quad(98.0)$ & $108.9 \pm 2.6 \quad(98.7)$ \\
\hline 42 & $109.1 \pm 3.2$ & $(98.8)$ & $113.2 \pm 2.3(102.5)$ & $111.7 \pm 2.3(101.2)$ \\
\hline 56 & $109.1 \pm 2.0$ & $(98.8)$ & $113.2 \pm 1.9(102.5)$ & $112.5 \pm 4.3(101.9)$ \\
\hline 84 & $110.8 \pm 2.3$ & $(100.4)$ & $108.9 \pm 8.8 \quad(98.7)$ & $114.2 \pm 3.7(103.4)$ \\
\hline 98 & $109.7 \pm 6.7$ & (99.4) & $112.6 \pm 6.6(102.0)$ & $109.1 \pm 4.2$ \\
\hline 120 & $111.1 \pm 4.5$ & $(100.6)$ & $111.0 \pm 3.5(100.5)$ & $111.0 \pm 3.7(100.6)$ \\
\hline $\begin{array}{l}\% \text { remaining at } \\
91 \text { days }\end{array}$ & & 102.3 & 102.0 & 101.5 \\
\hline $\begin{array}{l}\text { Lower limit of } 95 \% \\
\mathrm{Cl} \text { of } \% \text { remaining }\end{array}$ & & 100.4 & 98.7 & 98.0 \\
\hline
\end{tabular}

\section{References}

1. Pradaxa product monograph. Ingelheim am Rhein (Germany): Boehringer Ingelheim International GmbH; 2013 Jan 17.

2. Pradaxa product monograph. Burlington $(\mathrm{ON})$ : Boehringer Ingelheim Canada Ltd; 2014 Jun 24.

3. Pradaxa product monograph. Ridgefield (CT): Boehringer Ingelheim Pharmaceuticals, Inc; 2014 April.

4. Stangier J. Clinical pharmacokinetics and pharmacodynamics of the oral direct thrombin inhibitor dabigatran etexilate. Clin Pharmacokinet. 2008;47(5): 285-95.

5. CHMP assessment report for Pradaxa. London (UK): European Medicines Agency; 2008 [cited 2013 Mar 11]. Available from: www.ema.europa.eu/ docs/en_GB/document_library/EPAR___Public_assessment_report/human/ 000829/WC500041062.pdf

6. Product monograph: Pradaxa dabigatran etexilate capsules. In: Health Canada drug product database. Ottawa (ON): Health Canada; [cited 2014 Jul 2]. Available from: http://webprod5.hc-sc.gc.ca/dpd-bdpp/index-eng.jsp

7. Bernardi RM, Fröehlich PE, Bergold AM. Development and validation of a stability-indicating liquid chromatography method for the determination of dabigatran etexilate in capsules. J AOAC Int. 2013;96(1):37-41.

Erica H Z Wang, BScPharm, PharmD, ACPR, BCPS, is a Clinical Pharmacy Specialist in the Pharmacy Department, St Paul's Hospital, Vancouver, British Columbia.

Jennifer L Bolt, BSCPharm, ACPR, PharmD, is Residency and Education Coordinator in the Pharmacy Department, Regina Qu'Appelle Health Region, Regina, Saskatchewan.
Diane Décarie, BSC, is a Research Consultant in the Department of Pharmacy, Children's and Women's Health Centre of British Columbia, Vancouver, British Columbia.

William Semchuk, MSc, PharmD, FCSHP, is Manager of Pharmacy Practice, Regina Qu'Appelle Health Region, Regina, Saskatchewan.

Mary H H Ensom, BS(Pharm), PharmD, FASHP, FCCP, FCSHP, FCAHS, is a Professor in the Faculty of Pharmaceutical Sciences and Distinguished University Scholar, The University of British Columbia, and a Clinical Pharmacy Specialist, Children's and Women's Health Centre of British Columbia, Vancouver, British Columbia. She is also the Editor of the CJHP.

Competing interests: William Semchuk has received speaker's honoraria from AstraZeneca, Bayer, Boehringer Ingelheim, and Pfizer/BMS; research grants from Bayer, Pfizer, and Sanofi; and has served on advisory boards for Bristol-Myers Squibb, Pfizer Leo, and Sanofi. No other competing interests declared.

\section{Address correspondence to:}

Dr Erica H Z Wang

Pharmacy Department

St Paul's Hospital

1081 Burrard Street

Vancouver BC V6Z 1 Y 6

e-mail: ewang@providencehealth.bc.ca

Funding: Funding for this project was provided by a grant from the Regina Qu'Appelle Health Region. The grantor was not involved in the design and conduct of the study; the collection, management, or interpretation of the data; or the preparation, review, or approval of the manuscript. 